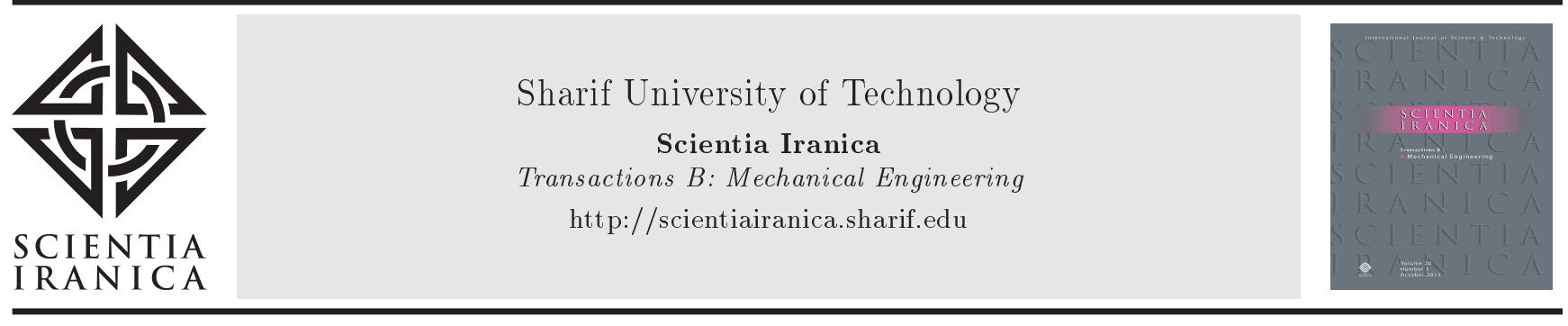

\title{
Thermoelastic deflection responses of CNT reinforced sandwich shell structure using finite-element method
}

\author{
K. Mehar ${ }^{a, *}$, S.K. Panda ${ }^{a}$, and T.R. Mahapatra ${ }^{b}$ \\ a. Department of Mechanical Engineering, National Institute of Technology, Rourkela, Odisha, 769008, India. \\ b. School of Mechanical Engineering, KIIT University, Bhubaneswar, Odisha, 751024, India. \\ Received 21 April 2017; received in revised form 2 June 2017; accepted 11 September 2017
}

KEYWORDS
Sandwich panel;
CNT;
HSDT;
FEM;
Thermoelastic
response;
Nonuniform
temperature loading.

\section{Introduction}

Sandwich structures have numerous applications in modern engineering such as aerospace, marine, defence equipment, construction and automobile, where structures are not only stiff and strong, but also light in weight. In general, a sandwich structure consists of three layers, i.e., two face sheets and one core layer, to attain the superior strength and stiffness properties. In a sandwich construction, the core layer (reasonably thicker than face sheets) made of the same or different

\footnotetext{
*. Corresponding author. Tel.: 0661-2462529

E-mail addresses: kulmanimehar@gmail.com (K. Mehar); pandask@nitrkl.ac.in (S.K. Panda);

trmahapatrafme@kiit.ac.in (T.R. Mahapatra)
}

materials is constrained with by means of two stiff face sheets (upper and bottom). When a substantial deviation of elastic properties between sandwich layers (core and face sheet) exists, the sandwich structural component may encounter delamination of the face sheet and the core layer, especially under impact loading [1]. Further, to reduce the unexpected delamination, a new concept called Functionally Graded Material (FGM) is adopted to design sandwich structures [25]. In FGM, the composition of the material varies through the dimensions of the structure, i.e., along the length/breadth or through the thickness. Recently, the concept of FGM is further improved by incorporating carbon nanotubes (CNTs) into the structural components, namely functionally graded carbon nanotubes (FG-CNTs) [6-12]. The nanotubes are well known for their superior electrical, mechanical, and chemical, including temperature-related, properties over the avail- 
able advanced and/or conventional fibers. The elastic properties of carbon nanotube-reinforced composite (CNTRC) structure have been already investigated by the structural engineers using available simple and modified techniques. Some of the contributions related to the evaluation of the final properties of nanotubereinforced composite, including the effect of shape, size, and distribution, are discussed in the following lines. Liu and Chen [13] employed the circular Representative Volume Element (RVE) technique to examine CNTRC structural properties. Similarly, few more advanced techniques or tools have been utilised in the recent past by the researchers for the computation of mechanical, thermal, and thermomechanical properties of the CNT via Molecular Dynamic (MD) simulation [14,15] and Mori-Tanaka scheme [16] for the randomly distributed CNTRC panel. Further, Tounsi and his co-authors proposed new and modified shear deformation theories by reducing the number of unknown variables from the available kinematic theories to analyse layered composite and FGM, including the FGM under the elevated thermal environment [17-22]. In addition, few research articles have been reported regarding the implementation of the Higher-order Shear Deformation Theory (HSDT) for the linear/nonlinear structural (buckling, post-buckling and vibration) analysis of CNT-reinforced sandwich and layered composite using von-Karman nonlinear strain [23-25]. Similarly, buckling responses of a laminated rectangular sandwich plate under the elevated thermal loading are examined in [26]. Further, linear bending, vibration, and buckling responses of the Functionally Graded (FG) sandwich plate structure were investigated by Zenkour $[27,28]$ using various kinematic theories and the solution techniques. The First-order Shear Deformation Theory (FSDT) in association with vonKarman geometrical nonlinear strain was adopted by Yang et al. [29] for the investigation of the static responses of FGM sandwich plate structure. Imrak and Fetvaci [30] employed the Finite-Element Method (FEM) to compute deflection responses of the layered composite plate under the mechanical Uniformly Distributed Load (UDL). The effects of the uncertainty in the elastic properties of the laminated and sandwich composite structures and subsequent nonlinear eigenvalue solutions were reported by Chandrashekhar and Ganguli [31]. The effect of thermomechanical loading effect on the flexural and buckling behaviour of the FG sandwich plate structure was investigated using [32,33]. As discussed earlier, the HSDT kinematics was further utilised to model the sandwich and laminated composite panels to compute the static and dynamic behaviours by Mantari et al. [34]. Further, the free vibration frequencies of the FG sandwich structure were evaluated computationally by Hadji et al. [35] using a refined classical laminated plate theory including four variables. Khalili and Mohammadi [36] reported thermal free vibration frequency responses of the FG sandwich plate structure. Natarajan and Manickam [37] investigated the static and vibration responses of the FG sandwich plate using the HSDT kinematics. Recently, FEM was utilised by Kavalur et al. [38] to examine the bending behaviour of the FGCNT reinforced visco-elastic sandwich plate discussed in detail about the effect of different design parameters on the static behaviour. Tornabene et al. [39] reported the influences of CNT agglomeration on the frequency responses of FG-CNTRC curved panel. Similarly, the higher-order kinematic model was utilised to examine the stress and fracture responses of the laminated structure by Szekrenyes [40]. The effect of end constrained conditions on the nonlinear responses of the square steel plate structure was investigated and reported by Saha et al. [41]. In addition, few earlier researches were focused on the optimal design parameter of the structure using the modified techniques to achieve higher stiffness and strength without increasing the weight of the structure. In this regard, the optimised critical buckling load parameters of the laminated flat and the cylindrical structures were investigated by Topal and Uzman [42,43] using the Modified Feasible Direction (MFD) method in association with the FSDT mid-plane kinematic. Similarly, the maximum natural frequencies of the laminated composite structure were already computed by Apalak et al. [44] using the individual and coupled soft computing techniques (artificial neural network; ANN and genetic algorithms; GA).

From the above extensive review, it was clearly understood that various attempts were made in the past to investigate the CNTRC structure using available and modified theories and solution techniques. However, the review reveals that no attempts have been made yet to compute the deflection responses of the CNT sandwich shell structure of different configuration panels using a flexible higher-order kinematic theory. In order to fill in the necessary gap, the current article aims to investigate the linear deflection responses of the CNT-reinforced sandwich curved (single/doubly) shell panel numerically using the FEM, including the HSDT kinematics, under the influence of variable temperature (uniform/linear) filed. Further, the constancy and consistency of the current numerical solutions were established via subsequent convergence including the necessary comparison analysis. Finally, the influence of various parameters (aspect ratio, core-to-face thickness ratio, volume fraction, length-to-thickness ratio, support condition, and curvature ratio) on CNT-reinforced sandwich panel structural deflection strength was evaluated by solving different numerical examples and discussed in detail. 


\section{Mathematical modelling of CNT sandwich shell}

In this research article, the CNT-reinforced sandwich panel structure is assumed to be made up of three different layers, say, two stiff face sheets of the FGCNT/epoxy reinforced composite bounded the upper and lower surfaces of one isotropic core layer (made of pure epoxy). The different layers of the sandwich structure are assumed to be perfectly bonded with each other and do not separate under the action of external transverse load. Further, various shell geometries, i.e., cylindrical (CYL; $R_{1}=R$ and $R_{2}=\infty$ ), spherical ( $\mathrm{SPH} ; R_{1}=R_{2}=R$ ), hyperbolic (HYP; $R_{1}=R$ and $R_{2}=-R$ ), and elliptical (ELL; $R_{1}=R$ and $R_{2}=$ $2 R$ ), are analysed in this article. Figure 1 presents a pictorial view of CNT-reinforced sandwich structural geometry. The associated geometrical parameter of the CNT sandwich, such as length ' $a$ ' and width ' $b$ ', include the total thickness ' $h$ '. The thickness of the sandwich has further two distinct values, i.e., core thickness ' $t_{c}$ ' and thickness of individual face sheets ' $t_{f}$ '.

\subsection{CNT gradations and elastic properties}

As mentioned earlier, the face sheets of the current sandwich panel model have been developed assuming either CNT graded using specific function (through the thickness) or Uniformly Distributed (UD). In this regard, two types of grading (FG- $\Lambda$ and $F G-\mathrm{V}$ ) of CNT for the face sheets of the FG-CNT-reinforced sandwich curved panel are modelled mathematically for the analysis purpose. The grading patterns are usually dependent on the volume fractions, i.e., when the concentration of the CNT increases linearly from zero (top surface) to twice the volume fraction of CNT $\left(V_{\mathrm{CNT}}^{*}\right)$ (the bottom) called $\mathrm{FG}-\Lambda$ type, whereas the alternating ratio of CNT fraction from top to bottom faces will be termed as FG-V, respectively. Now, the CNT distribution and the corresponding CNT volume fraction of the current sandwich construction are expressed using simple mathematical steps [45]:

- For FG-CNT reinforced sandwich curved panel:

$$
\begin{array}{l|l}
V_{\mathrm{CNT}}=2\left(\frac{h_{1}-z}{h_{1}-h_{0}}\right) V_{\mathrm{CNT}}^{*} \\
V_{\mathrm{CNT}}=0 \\
V_{\mathrm{CNT}}=2\left(\frac{z-h_{2}}{h_{3}-h_{2}}\right) V_{\mathrm{CNT}}^{*}
\end{array}\left\{\begin{array}{l}
\text { for lower face sheet } \\
z \in\left\{h_{0}, h_{1}\right\} \\
\text { for core } \\
z \in\left\{h_{1}, h_{2}\right\} \\
\text { for upper face sheet } \\
z \in\left\{h_{2}, h_{3}\right\}
\end{array}\right.
$$

- For UD-CNT reinforced sandwich curved panel:

$$
\left.\begin{array}{l}
V_{\mathrm{CNT}}=V_{\mathrm{CNT}}^{*} \\
V_{\mathrm{CNT}}=0
\end{array}\right\} \begin{aligned}
& \text { for upper and lower face sheets } \\
& \text { for core }
\end{aligned}
$$

or:

$$
V_{\mathrm{CNT}}^{*}=\frac{w_{\mathrm{CNT}}}{w_{\mathrm{CNT}}+\left(\frac{\rho^{\mathrm{CNT}}}{\rho^{m}}\right)-\left(\frac{\rho^{\mathrm{CNT}}}{\rho^{m}}\right) w^{\mathrm{CNT}}},
$$

where $V_{\mathrm{CNT}}^{*}$ is the total CNT volume fraction within the upper and lower face sheets, $w_{\mathrm{CNT}}$ is the CNT weight fraction, and $\rho$ is the density. Superscripts " $m$ " and "CNT" represent matrix and CNT, respectively.

Further, the extended rule of mixture is implemented to evaluate the elastic properties of the CNT-reinforced sandwich construction including the assumption of CNT alignment along the longitudinal axis ( $x$-axis), conceded as follows [46,47]:

$$
\begin{aligned}
& E_{11}=\eta_{1} V_{\mathrm{CNT}} E_{11}^{\mathrm{CNT}}+V_{m} E^{m}, \\
& \frac{\eta_{2}}{E_{22}}=\frac{V_{\mathrm{CNT}}}{E_{22}^{\mathrm{CNT}}}+\frac{V_{m}}{E^{m}},
\end{aligned}
$$

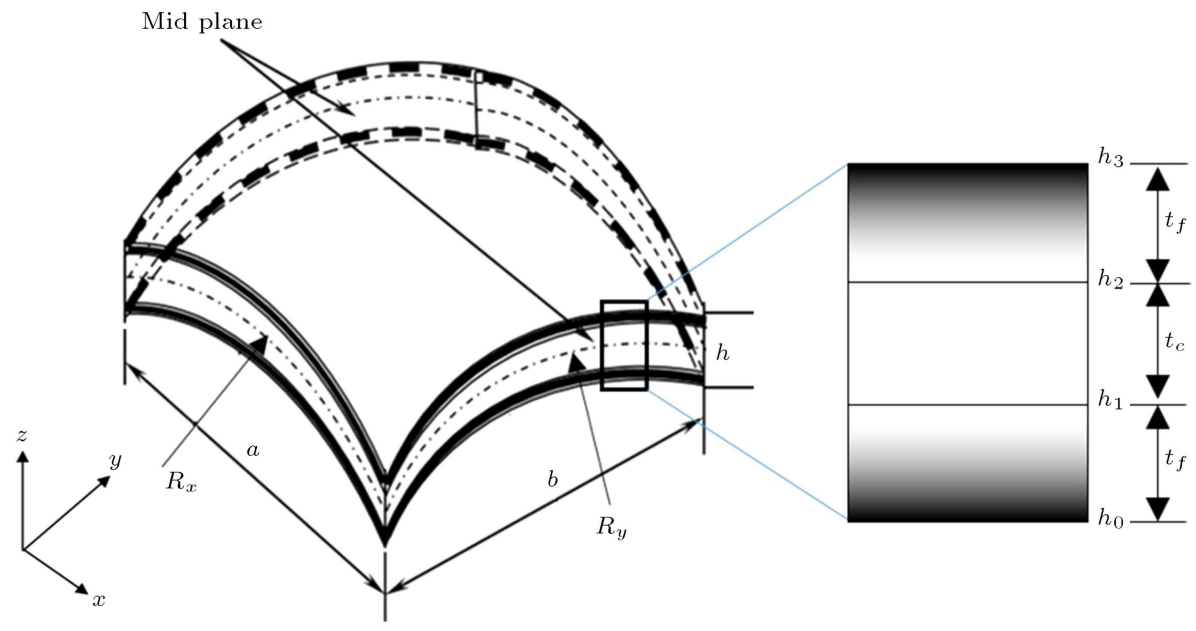

Figure 1. Geometry of sandwich curved shell panel. 


$$
\frac{\eta_{3}}{G_{12}}=\frac{V_{\mathrm{CNT}}}{G_{12}^{\mathrm{CNT}}}+\frac{V_{m}}{G^{m}} .
$$

In general, the sum of the total volume fractions of the matrix and fiber in the composite construction is equal to unity. Therefore, the individual volume fractions of the matrix contained in the face sheets of the sandwich panel can be obtained using the following mathematical relation:

$$
V_{m}=1-V_{\mathrm{CNT}} \text {. }
$$

Additionally, few more properties associated with the material necessary for the current analysis, i.e., the direction-dependent thermal conductivity $\left(k_{11}\right.$ and $\left.k_{22}\right)$, Poisson's ratio $\left(v_{12}\right)$, density $(\rho)$, and coefficients of thermal expansion $\left(\alpha_{11}\right.$ and $\left.\alpha_{22}\right)$ along the corresponding material axes, are evaluated using the common rule of mixture $[47,48]$ :

$$
\begin{aligned}
v_{12}= & V_{\mathrm{CNT}} v_{12}^{\mathrm{CNT}}+V_{m} v^{m}, \\
\rho= & V_{\mathrm{CNT}} \rho^{\mathrm{CNT}}+V_{m} \rho^{m}, \\
\alpha_{11}= & V_{\mathrm{CNT}} \alpha_{11}^{\mathrm{CNT}}+V_{m} \alpha^{m}, \\
\alpha_{22}= & \left(1+v_{12}^{\mathrm{CNT}}\right) V_{\mathrm{CNT}} \alpha_{22}^{\mathrm{CNT}}+\left(1+v^{m}\right) V_{m} \alpha^{m} \\
& -v_{12} \alpha_{11}, \\
k_{11}= & V_{\mathrm{CNT}} k_{11}^{\mathrm{CNT}}+V_{m} k^{m}, \\
\frac{1}{k_{22}}= & \frac{V_{\mathrm{CNT}}}{k_{22}^{\mathrm{CNT}}}+\frac{V_{m}}{k^{m}}, \\
\frac{1}{k_{33}}= & \frac{V_{\mathrm{CNT}}}{k_{33}^{\mathrm{CNT}}}+\frac{V_{m}}{k^{m}} .
\end{aligned}
$$

\subsection{Temperature distribution across thickness}

In the present analysis, two different types of temperature distributions through the transverse direction of the sandwich structure are employed: uniformly distributed and linearly distributed temperature fields.

\subsubsection{Uniformly distributed temperature}

In the case of the uniformly distributed temperature field, the temperature is not varying through the thickness (z-direction) of the structural panel. Therefore, the mathematical expression for such a temperature distribution is as follows:

$$
T(z)=T_{t}
$$

where $T_{t}$ is the temperature at the top surface.

\subsubsection{Linearly distributed temperature}

The bottom surface temperature $\left(T_{b}\right)$ is assumed to be varying linearly to the top surface temperature $\left(T_{t}\right)$ through the thickness $(z)$ direction and is expressed as follows [49]:

$$
\begin{aligned}
T(z)= & T_{b}+\left(T_{t}-T_{b}\right)\left(\frac{z}{h}+\frac{1}{2}\right) \\
& -h / 2 \leq z \leq h / 2 .
\end{aligned}
$$

\subsection{Kinematics and constitutive relations}

The CNT-reinforced sandwich panel structure is modelled mathematically via a simple higher-order kinematics as in [50-52], which is capable of including the necessary in-plane and out-of-plane stress and strain conditions.

$$
\begin{aligned}
u(x, y, z, t)= & u_{0}(x, y)+z u_{1}(x, y) \\
& +z^{2} u_{2}(x, y)+z^{3} u_{3}(x, y), \\
v(x, y, z, t)= & v_{0}(x, y)+z v_{1}(x, y) \\
& +z^{2} v_{2}(x, y)+z^{3} v_{3}(x, y), \\
w(x, y, z, t)= & w_{0}(x, y),
\end{aligned}
$$

where ' $u$ ', ' $v$ ', and ' $w$ ' represent the displacement variable functions along the corresponding coordinate axes ( $x, y$, and $z$ directions) of any point within the structural panel. Now, the terms associated with subscript ' 0 ' represent the values defined at the midsurface $(z=0)$ of the sandwich structure, whereas $u_{1}$ and $v_{1}$ correspond to the rotation about $y$ and $x$ axes at mid-plane. In addition, a few more coefficients as seen in Eq. (16) $\left(u_{2}, v_{2}, u_{3}\right.$ and $\left.v_{3}\right)$ are included to model deformation kinematics of CNT-reinforced sandwich structure with adequate accuracy. Further, the equation is rearranged in the matrix form in the following lines:

$$
\{\lambda\}=[f]\left\{\lambda_{0}\right\}
$$

where:

$$
\{\lambda\}=\{u v w\}^{T},
$$

is the total displacement field vector,

$$
\left\{\lambda_{0}\right\}=\left\{\begin{array}{lllllllll}
u_{0} & v_{0} & w_{0} & u_{1} & v_{1} & u_{2} & v_{2} & u_{3} & v_{3}
\end{array}\right\}^{T},
$$

is displacement field vector at $z=0$, and

$$
[f]=\left[\begin{array}{ccccccccc}
1 & 0 & 0 & z & 0 & z^{2} & 0 & z^{3} & 0 \\
0 & 1 & 0 & 0 & z & 0 & z^{2} & 0 & z^{3} \\
0 & 0 & 1 & 0 & 0 & 0 & 0 & 0 & 0
\end{array}\right]
$$

is the thickness coordinate matrix.

Now, the necessary strain values of the CNTreinforced sandwich structural panel are obtained using the current displacement field via general straindisplacement relations for the curved structure: 


$$
\begin{aligned}
\{\varepsilon\} & =\left\{\begin{array}{c}
\varepsilon_{x x} \\
\varepsilon_{y y} \\
\gamma_{x y} \\
\gamma_{z x} \\
\gamma_{y z}
\end{array}\right\}=\left\{\begin{array}{c}
\frac{\partial u}{\partial x}+\frac{w}{R_{x}} \\
\frac{\partial v}{\partial y}+\frac{w}{R_{y}} \\
\frac{\partial u}{\partial y}+\frac{\partial v}{\partial x}+2 \frac{w}{R_{x y}} \\
\frac{\partial u}{\partial z}+\frac{\partial w}{\partial x}-\frac{u}{R_{x}} \\
\frac{\partial v}{\partial z}+\frac{\partial w}{\partial y}-\frac{v}{R_{y}}
\end{array}\right\} \\
& =\left\{\begin{array}{c}
\varepsilon_{x}^{0} \\
\varepsilon_{y}^{0} \\
\gamma_{x y}^{0} \\
\gamma_{z x}^{0} \\
\gamma_{y z}^{0}
\end{array}\right\}+z\left\{\begin{array}{c}
\varsigma_{x} \\
\varsigma_{y} \\
\varsigma_{x y} \\
\varsigma_{z x} \\
\varsigma_{y z}
\end{array}\right\}+z^{2}\left\{\begin{array}{c}
\zeta_{x} \\
\zeta_{y} \\
\zeta_{x y} \\
\zeta_{z x} \\
\zeta_{y z}
\end{array}\right\}+z^{3}\left\{\begin{array}{c}
\xi_{x} \\
\xi_{y} \\
\xi_{x y} \\
\xi_{z x} \\
\xi_{y z}
\end{array}\right\},(18)
\end{aligned}
$$

or:

$$
\{\varepsilon\}=[H]\{\bar{\varepsilon}\},
$$

where $\{\bar{\varepsilon}\}$ is the strain vector at $z=0$, and matrix $[H]$ is the thickness coordinate matrix; details are illustrated in the Appendix.

Now, a thermoelastic constitutive relation is employed for the CNT-reinforced sandwich panel to evaluate stress tensor according to the generalised Hooke's law, including the influence of the thermal field, expressed as follows:

$$
\begin{aligned}
\left\{\begin{array}{l}
\sigma_{x x} \\
\sigma_{y y} \\
\tau_{x y} \\
\tau_{z x} \\
\tau_{y z}
\end{array}\right\}^{k} & {\left[\begin{array}{ccccc}
Q_{11} & Q_{12} & 0 & 0 & 0 \\
Q_{21} & Q_{22} & 0 & 0 & 0 \\
0 & 0 & Q_{33} & 0 & 0 \\
0 & 0 & 0 & Q_{55} & 0 \\
0 & 0 & 0 & 0 & Q_{44}
\end{array}\right]^{k} } \\
& \left(\left\{\begin{array}{c}
\varepsilon_{x x} \\
\varepsilon_{y y} \\
\gamma_{x y} \\
\gamma_{z x} \\
\gamma_{y z}
\end{array}\right\}-\left\{\begin{array}{c}
\alpha_{11} \\
\alpha_{22} \\
0 \\
0 \\
0
\end{array}\right\} \Delta T\right)^{k},
\end{aligned}
$$

or:

$$
\{\sigma\}^{k}=[Q]^{k}\{\varepsilon-\alpha \Delta T\}^{k},
$$

where $Q_{11}=\frac{E_{11}}{1-v_{12} v_{21}}, Q_{12}=\frac{v_{12} E_{22}}{1-v_{12} v_{21}}, Q_{22}=\frac{E_{22}}{1-v_{12} v_{21}}$, $Q_{33}=G_{12}, Q_{44}=G_{13}, Q_{55}=G_{23}, G_{13}=G_{23}=G_{12}$, and $k$ indicates the number of layers (1 for the lower face sheet, 2 for the core layer, and 3 for the upper face sheet).

\subsection{Finite-element formulation}

Further, $C^{0}$ finite-element steps are employed to discretise the CNT-reinforced sandwich panel model by means of a nine-node Lagrangian element including the nine degrees of freedom at each node. Now, the displacement finite-element model is implemented in the total displacement field $\left\{\lambda_{0}\right\}$ via the nodal displacement filed vector $\left(\left\{\lambda_{0 i}\right\}=\right.$ $\left.\left[\begin{array}{lllllllll}u_{0_{i}} & v_{0_{i}} & w_{0_{i}} & \varphi_{x_{i}} & \varphi_{y_{i}} & \psi_{x_{i}} & \psi_{y_{i}} & \theta_{x_{i}} & \theta_{y_{i}}\end{array}\right]^{T}\right)$, including the necessary shape functions $\left(N_{i}\right)$, and is mathematically expressed as follows [53]:

$$
\left\{\lambda_{0}\right\}=\sum_{i=1}^{9} N_{i}\left\{\lambda_{0 i}\right\},
$$

where subscript " $i$ " represents the node number.

\subsection{Governing equation}

Now, the variational technique is employed to minimise the total energy functional for the derivation of the final form of the equilibrium equation of the deflected CNTreinforced sandwich panel structure presented in the following form:

$$
\delta \prod=\delta U-\delta W=0
$$

where $\Pi, U$, and $W$ represent the total potential energy, strain energy, and work done, respectively.

The total strain energy of the CNT-reinforced sandwich structural shell panel can be computed as follows:

$$
U=\frac{1}{2} \iint\left\{\sum_{k=1}^{3} \int_{z_{k-1}}^{z_{k}}\{\varepsilon\}^{T}[Q]\{\varepsilon\} d z\right\} d x d y .
$$

Now, Eq. (24) is rearranged further by substituting the values of stress and strains rewritten in the following form:

$$
U=\frac{1}{2} \iint\left(\{\bar{\varepsilon}\}^{T}[D]\{\bar{\varepsilon}\}\right) d x d y,
$$

where:

$$
[D]=\left\{\sum_{k=1}^{3} \int_{z_{k-1}}^{z_{k}}[H]^{T}[Q][H] d z\right\} .
$$

The static deflections of the CNT-reinforced sandwich structure are evaluated numerically under two types of mechanical loading $(p)$. The corresponding mathematical expressions of the individual loading types are presented as in the following [54]:

- Uniformly Distributed Load (UDL):

$$
p(x, y)=q_{0}
$$

- Sinusoidally Distributed Load (SDL):

$$
p(x, y)=q_{0} \sin (\pi x / a) \sin (\pi y / b) .
$$

Now, the total work done due to the combined effect of the mechanical and temperature loading is expressed using steps as in the following [46]: 


$$
\begin{aligned}
W= & \iint \sum_{k=1}^{3}\left(\left\{\lambda_{0}\right\}^{T}\{p\}\right) d x d y \\
& +\iint \sum_{k=1}^{3}\left(\{\varepsilon\}^{T}[Q]\left\{\varepsilon_{t h}\right\}\right) d x d y,
\end{aligned}
$$

or:

$$
W=\left\{\lambda_{0}\right\}^{T}\left\{F_{m}\right\}+\left\{\lambda_{0}\right\}^{T}\left\{F_{t h}\right\},
$$

where $\left\{F_{t h}\right\}$ is the thermal load vector, and $\left\{F_{m}\right\}$ is the mechanical load vector.

Lastly, the final form of the equilibrium equation of the deflected CNT-reinforced sandwich panel is derived by inserting different unknowns (the work done and strain energy functional) into Eq. (23) and is rearranged as follows:

$$
\left[K_{s}\right]\left\{\lambda_{s}\right\}=\{P\}
$$

where $\left\{\lambda_{s}\right\},\left[K_{s}\right]$, and $\{P\}$ are the corresponding displacement field, system stiffness, and force matrices, respectively.

\section{Results and discussion}

In this research, the static deflection values of the FG-CNT-reinforced sandwich curved shell panel have been obtained numerically via an original computer code (MATLAB) including the current higher-order FE model. The face sheets of the sandwich shell panel are made by the CNT reinforced composite material, and the core phase is made by isotropic and homogeneous material, poly (methyl methacrylate), referred to as PMMA. The PMMA is assumed to be temperature dependent, and material properties are considered as $\rho=1150 \mathrm{~kg} / \mathrm{m}^{3}, E^{m}=(3.52-0.0034 T) \times 10^{9} \mathrm{~Pa}$, and $\alpha=45(1000+0.5 \Delta T) \times 10^{-9}[55]$, where $\Delta T=T-T_{0}$ and $T_{0}=300 \mathrm{~K}$ (ambient temperature). The singlewalled carbon nanotubes (SWCNTs) are employed as reinforcement materials for the face sheets of sandwich construction. Further, the operational elastic properties of SWCNT, including effectiveness parameters $\left(\eta_{i}\right)$ and individual elastic constants, the same as those in [56], are assessed. Now, the elastic properties under the elevated temperature loading (uniform and linear) are evaluated using the following polynomial expressions as in the source.

$$
\begin{array}{r}
E_{11}^{\mathrm{CNT}}(\mathrm{TPa})=6.3998-4.338417 \times 10^{-3} T \\
\quad+7.43 \times 10^{-6} T^{2}-4.45833 \times 10^{-9} T^{3}, \\
E_{22}^{\mathrm{CNT}}(\mathrm{TPa})=8.02155-5.420375 \times 10^{-3} T \\
\quad+9.275 \times 10^{-6} T^{2}-5.5625 \times 10^{-9} T^{3},
\end{array}
$$

$$
\begin{gathered}
G_{12}^{\mathrm{CNT}}(\mathrm{TPa})=1.40755+3.476208 \times 10^{-3} T \\
-6.965 \times 10^{-6} T^{2}+4.479167 \times 10^{-9} T^{3}, \\
\alpha_{11}^{\mathrm{CNT}}\left(10^{-6} / \mathrm{K}\right)=-1.12515+0.02291688 T \\
\quad-2.887 \times 10^{-5} T^{2}+1.13625 \times 10^{-8} T^{3}, \\
\alpha_{22}^{\mathrm{CNT}}\left(10^{-6} / \mathrm{K}\right)=5.43715-0.984625 \times 10^{-4} T \\
+2.9 \times 10^{-7} T^{2}+1.25 \times 10^{-11} T^{3} .
\end{gathered}
$$

In this numerical analysis, the thermal conductivity of CNT is assumed to be temperature independent, and the values are taken to be same as those in [56]. Now, the values of conductivities for the corresponding principal material directions include $k_{11}^{\mathrm{CNT}}=3000 \mathrm{w} / \mathrm{mK}$, $k_{22}^{\mathrm{CNT}}=k_{33}^{\mathrm{CNT}}=100 \mathrm{w} / \mathrm{mK}$, and $k^{m}=5 \mathrm{w} / \mathrm{mK}$.

In the current analysis, the following type support conditions are used:

a. Simply-supported at the edges $(\mathrm{S})$ :

$$
v=w=\varphi_{y}=\psi_{y}=\theta_{y}=0 \quad \text { for } \quad x=0, a,
$$

and:

$$
u=w=\varphi_{x}=\psi_{x}=\theta_{x}=0 \quad \text { for } \quad y=0, b .
$$

b. Clamped at the edges $(\mathrm{C})$ :

$$
\begin{aligned}
& u=v=w=\varphi_{x}=\varphi_{y}=\psi_{x}=\psi_{y}=\theta_{x}=\theta_{y}=0 \\
& \text { for both } x=0, a \text { and } y=0, b .
\end{aligned}
$$

c. Hinged at the edges $(\mathrm{H})$ :

$$
u=v=w=\varphi_{y}=\psi_{y}=\theta_{y}=0 \quad \text { for } \quad x=0, a,
$$

and:

$$
u=v=w=\varphi_{y}=\psi_{y}=\theta_{y}=0 \quad \text { for } \quad y=0, b .
$$

d. Free at the edges $(\mathrm{F})$ :

No restriction at the free end edge.

Through the combination of the above end edge support conditions, five different sets of the support conditions, such as SSSS (simply supported at all four edges), CCCC (clamped at all four edges), $\mathrm{HHHH}$ (hinged at all four edges), CSCS (two opposite edges are clamped and two others are simply supported), and CFCF (two opposite edges are clamped and two others are free) have been utilised to examine the static responses. In this present investigation, the central deflection of the sandwich curved panel is normalized using formula $\bar{w}=w_{c} / h$, where $w_{c}$ is the maximum central deflection of the sandwich structure. Additionally, the deflection responses of the CNT-reinforced sandwich structure are computed for different values of core-to-face thickness ratios $\left(t_{c} / t_{f}\right)$ throughout the analysis, considering that the total thickness is constant for different non-dimensional thickness values, i.e., ' $z / h$ '. 


\subsection{Convergence and validation study}

The significance of the convergence and subsequent validity study of any numerical solution, such as FEM, is well known. Hence, the currently developed higherorder FE model is employed to compute the deflection parameters for different mesh sizes of the FG-CNTreinforced sandwich curved panel structure (all sides are simply supported). The responses are computed for four different geometries and five core-to-face thickness ratios $\left(t_{c} / t_{f}\right)$ and depicted in Figure 2(a) and (b), respectively $\left(h=5 \mathrm{~mm}, a / h=50, V_{\mathrm{CNT}}^{*}=0.12\right.$, and $a / b=1$ at $300 \mathrm{~K})$. The figures indicate that the numerical responses obtained by the current $\mathrm{FE}$ model converge well from coarse to the fine mesh. Subsequently, a $(6 \times 6)$ mesh is employed to compute deflection values of all different kinds of geometries, including the associated parameters.

It is necessary to mention that the deflection results of FG-CNT-reinforced sandwich shell structure are not available in the open literature. Now, the validity of the current numerical model is demonstrated by solving few problems related to the laminated structure using the currently developed higher-order model. In this regard, the results are obtained using the example problem the same as that in $[57,58]$, as shown in Table 1. The results are obtained for different curvature ratios $(R / a)$ and two length-to-thickness ratios $(a / h=10$ and 100$)$, including the necessary elastic properties $\left(E_{1}=25.0 E_{2}, G_{12}=G_{13}=0.5 E_{2}\right.$, $G_{23}=0.2 E_{2}$, and $\left.v_{12}=0.25\right)$, as provided in $[57,58]$. Further, the central deflection parameter is normalised using the formula provided in [58]:

$$
\bar{w}=\left(10^{3} h w_{c} E_{0}\right) / a^{2} p
$$

where $E_{0}=1 \mathrm{GPa}$. The comparison study illustrates that the developed higher-order FE model is capable of solving a wide range of shell problems, i.e., thin to moderately thick shallow shell panels with adequate accuracy. Further, to improve the confidence in the current FE model, few results are computed for the FGM sandwich structure by changing the core-to-face thickness ratios and the power law indices $(n)$ under the mechanical SDL. The normalized central deflections are calculated using the same material and geometrical properties as those used in [59] and reported

Table 1. Comparison of normalized central deflections of the laminated $\left(0^{\circ} / 90^{\circ} / 0^{\circ}\right)$ spherical curved panel.

\begin{tabular}{clcccccc}
\hline \multirow{2}{*}{$/ \boldsymbol{h}$} & \multirow{2}{*}{ Method } & \multicolumn{7}{c}{$\boldsymbol{R} / \boldsymbol{a}$} \\
\cline { 3 - 8 } & & $\mathbf{5}$ & $\mathbf{1 0}$ & $\mathbf{2 0}$ & $\mathbf{5 0}$ & $\mathbf{1 0 0}$ & $\mathbf{1 0}^{\mathbf{9}}$ \\
\hline \multirow{3}{*}{100} & FSDT [57] & 1.0321 & 2.4099 & 3.617 & 4.2071 & 4.3074 & 4.3420 \\
& HSDT [57] & 1.0337 & 2.4109 & 3.615 & 4.2027 & 4.3026 & 4.3370 \\
& LWDT $^{\mathrm{a}}[58]$ & 1.0340 & 2.4120 & 3.6172 & 4.2055 & 4.3055 & 4.3400 \\
& Present & 1.0368 & 2.4224 & 3.6372 & 4.2313 & 4.3324 & 4.3672 \\
& & & & & & & \\
\multirow{2}{*}{10} & FSDT [57] & 6.7688 & 7.0325 & 7.1016 & 7.1212 & 7.1240 & 7.1250 \\
& HSDT [57] & 6.4253 & 6.6247 & 6.6756 & 6.6902 & 6.6923 & 6.6939 \\
& LWDT [58] & 7.0834 & 7.3252 & 7.3883 & 7.4061 & 7.4087 & 7.4095 \\
& Present & 6.8268 & 7.0405 & 7.0961 & 7.1118 & 7.114 & 7.1147 \\
\hline
\end{tabular}

${ }^{a}$ LWDT: Layer Wise Deformation Theory.

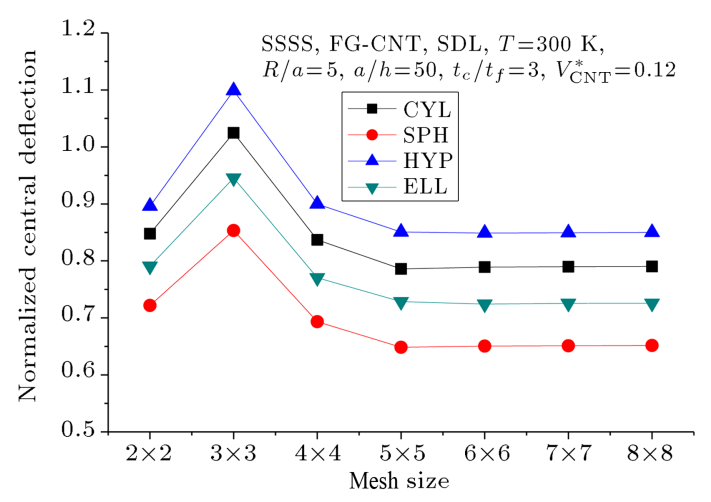

(a)

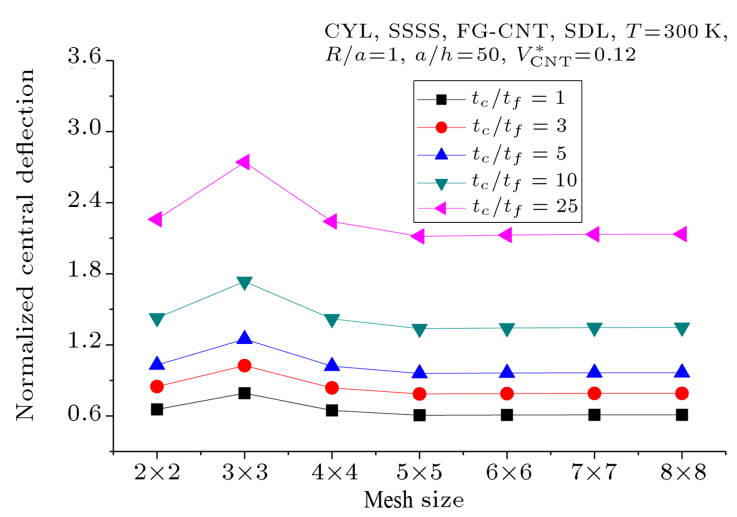

(b)

Figure 2. Convergence study of FG-CNT reinforced sandwich curved panel. 
Table 2. Comparison study of non-dimensional central deflections of simply supported FG sandwich plate under $\operatorname{SDL}\left(\bar{w}=w_{c}\left(10 h E_{0}\right) /\left(a^{2} q_{0}\right), a / h=10, a / b=1\right.$, $\left.E_{0}=1 \mathrm{GPa}\right)$.

\begin{tabular}{|c|c|c|c|c|c|}
\hline \multirow[t]{2}{*}{$n$} & \multirow[t]{2}{*}{ Theory } & \multicolumn{4}{|c|}{$\begin{array}{c}\text { Nondimensional central } \\
\text { deflection }(\bar{w})\end{array}$} \\
\hline & & 1-0-1 & $2-1-2$ & 1-1-1 & 1-2-1 \\
\hline \multirow{6}{*}{1} & TSDT [27] & 0.3236 & 0.3063 & 0.2920 & 0.2709 \\
\hline & $\mathrm{SSDT}^{\mathrm{a}}[27]$ & 0.3235 & 0.3062 & 0.2919 & 0.2709 \\
\hline & FSDT [27] & 0.3248 & 0.3075 & 0.2930 & 0.2717 \\
\hline & $\mathrm{CLPT}^{\mathrm{b}}[27]$ & 0.3105 & 0.2942 & 0.2803 & 0.2596 \\
\hline & FSDT [59] & 0.3237 & 0.3064 & 0.2920 & 0.2710 \\
\hline & Present & 0.3232 & 0.3059 & 0.2916 & 0.2706 \\
\hline \multirow{6}{*}{10} & TSDT [27] & 0.4177 & 0.4041 & 0.3855 & 0.3482 \\
\hline & SSDT [27] & 0.4175 & 0.4038 & 0.3849 & 0.3412 \\
\hline & FSDT [27] & 0.4192 & 0.4066 & 0.3879 & 0.3500 \\
\hline & CLPT [27] & 0.3988 & 0.3894 & 0.3724 & 0.3361 \\
\hline & FSDT [59] & 0.3988 & 0.3894 & 0.3724 & 0.3361 \\
\hline & Present & 0.4173 & 0.4038 & 0.3852 & 0.3478 \\
\hline
\end{tabular}

aSSDT: Second-order Shear Deformation Theory;

${ }^{\mathrm{b}}$ CLPT: Classical Laminated Plate Theory.

in Table 2 along with the results of the published literature $[27,59]$. From both of the comparison studies, it is evident that the results evaluated using the current higher-order FE model are as good as the available published results.

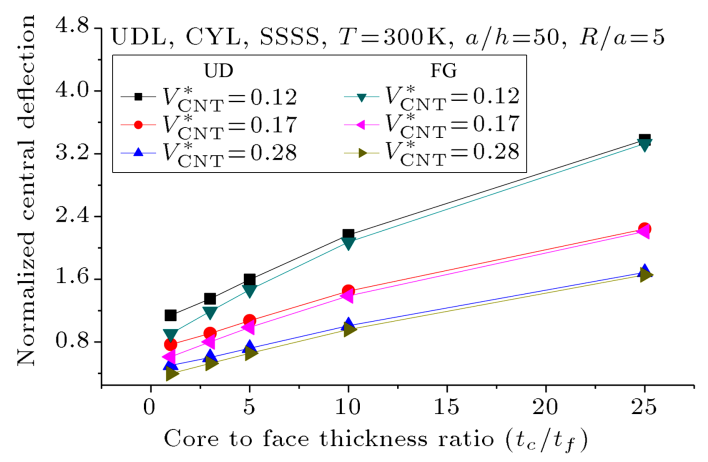

(a)

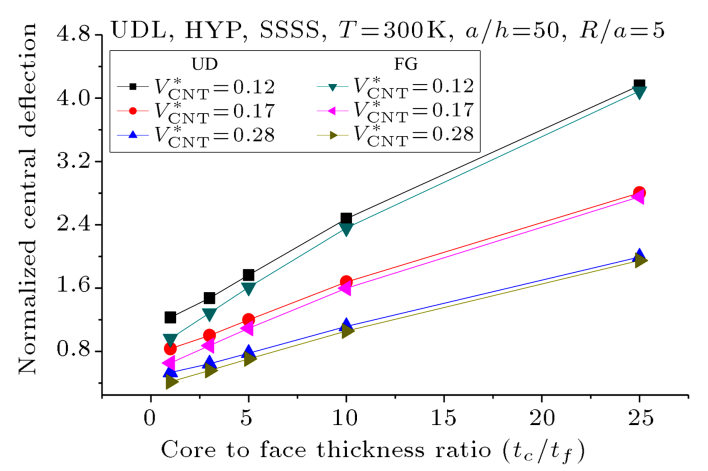

(c)

\subsection{Parametric study}

After a proper evaluation of the convergence and the comparison test, the presently developed FE model is engaged to evaluate the deflection responses of the CNT-reinforced sandwich structure of various shell geometries, including the influential parameter relevant to the geometry and elastic properties. In general, the static deflections values are computed for different values of $t_{c} / t_{f}$ and two types of grading configurations of CNT (UD-CNT and FG-CNT) at $300 \mathrm{~K}$ with $a / h=$ $50, V_{\mathrm{CNT}}^{*}=0.12, a / b=1$, and $h=0.005 \mathrm{~m}$ irrespective of each example, if not stated otherwise.

\subsubsection{Effect of CNT volume fraction}

Figure 3 shows the effect of CNT's volume fraction, i.e., $V_{\mathrm{CNT}}^{*}$, on the normalized deflection responses of all sides simply-supported CNT-reinforced sandwich curved shell panel for four different geometries and two CNT grading configurations at $300 \mathrm{~K}$ temperature. Based on the numerical results, the deflection parameter follows an increasing trend for the higher values $t_{c} / t_{f}$; however, the values show a reverse trend for the smaller values of $t_{c} / t_{f}$. The reason behind the expected regular results is the less stiff configuration of the CNTreinforced sandwich panel when $t_{c} / t_{f}$ value increases. Interestingly, the face sheet (stiffer than core) thickness decreases when $t_{c} / t_{f}$ value increases, and the overall stiffness of the sandwich panel decreases subsequently.

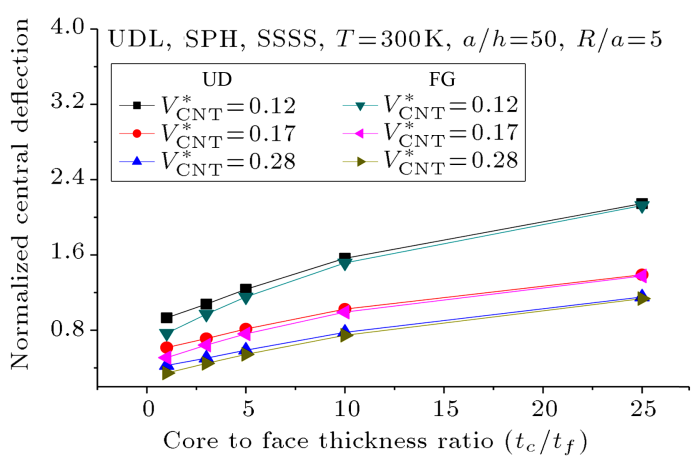

(b)

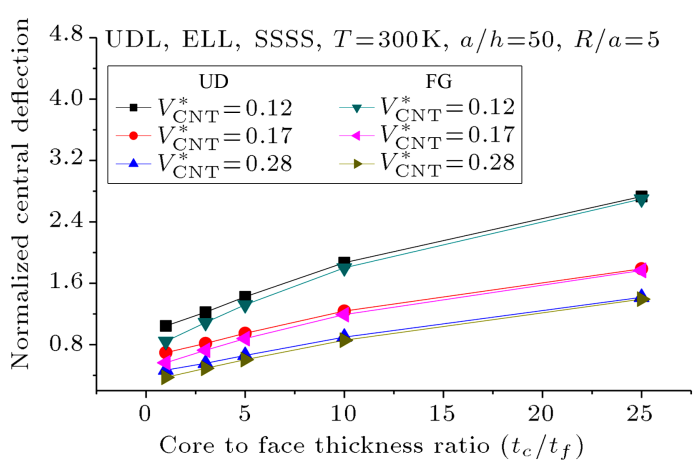

(d)

Figure 3. Effect of the volume fraction on deflection parameter of CNT-reinforced sandwich curved panel. 
In addition, the results indicate that the FG-CNT is the stiffer configuration when compared to the UD-CNT.

\subsubsection{Influence of curvature ratio on bending deflection}

The deflection responses of CNT-reinforced sandwich shell structures under the influence of the mechanical UDL are computed numerically for five curvature ratios $(R / a=1,2,5,10$, and 20$)$ and five of $t_{c} / t_{f}$, as plotted in Figure 4(a) and (b). The responses are obtained for two geometrical configurations (cylindrical and spherical) using the other geometrical and material parameters the same as discussed earlier. The bending deflection values follow an increasing trend when the curvature ratios increase as expected. The curved geometry possesses higher stiffness value in comparison to the flat panel, and the geometry becomes flat for the higher values of the curvature ratios. It is also notable that the effect of the core-to-face thickness ratio becomes more significant for higher values of curvature ratio.

\subsubsection{Aspect ratio effect of deflection responses}

The structural stiffness largely depends on the aspect ratio, which affects the final responses. Figure 5 shows the bending responses of four sandwich shell geometries made of FG-CNT for five aspect ratios and six coreto-face thickness ratios. The results indicate that the deflection parameter of the sandwich panel structure decreases when the aspect ratio increases, whereas the values follow a reverse trend for the core-to-face thickness ratio.

\subsubsection{Effect of length-to-thickness ratio}

Figure 6 illustrates the influence of the length-tothickness ratio on the normalized central deflection of FG-CNT reinforced sandwich curved panels of four different geometries and five core-to-face thickness ratios $\left(t_{c} / t_{f}=1,3,5,10\right.$ and 25$)$. Figure 6 shows that the normalized central deflection of the sandwich curved panel increases with both the lengthto-thickness and core-to-face thickness ratios. It is also inferred that the stiffness of the spherical geometry is the highest as compared to other three geometries, and the normalized central deflection of different geometries diverges at the higher value of length-to-thickness ratio.

\subsubsection{Effect of support conditions}

It is well known that the stiffness of the composite structure is highly influenced by the support condition on the edges. Table 3 shows that the normalized central deflection of the CCCC-type support condition is the least, as compared to all other four sets of support conditions, because the number of constraints in the CCCC-type support condition is the highest, as compared to all other support conditions. Table 3 shows that the central deflection of the CNT reinforced

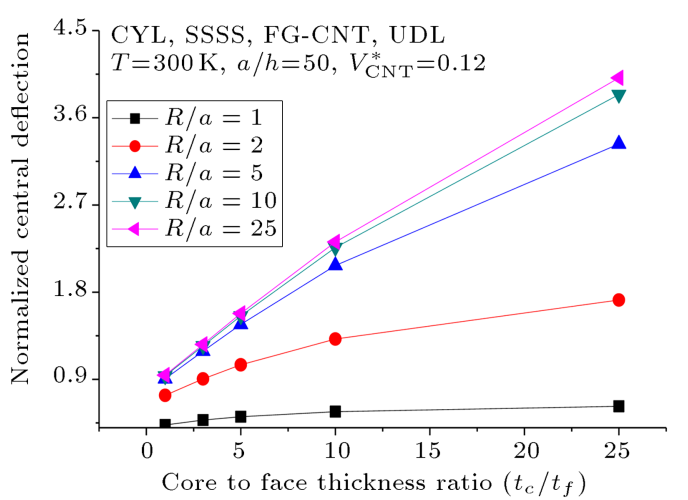

(a)

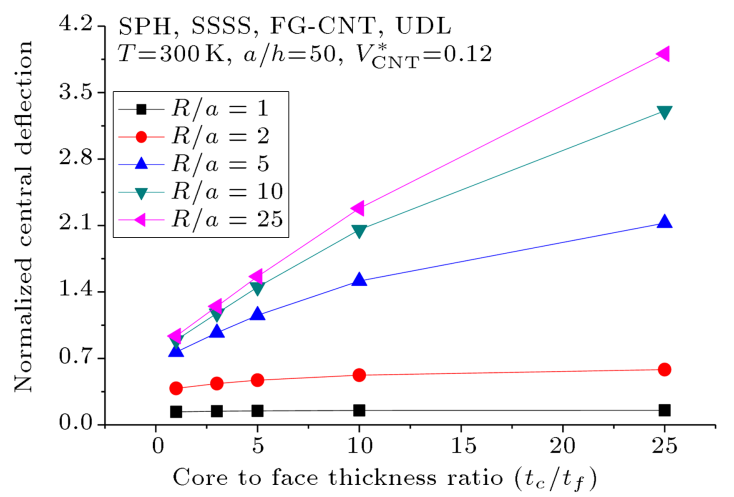

(b)

Figure 4. Effect of the curvature ratio on the central deflection of FG-CNT reinforced sandwich curved panel.

Table 3. Effect of support conditions on normalized central deflection of FG-CNT-reinforced sandwich cylindrical panel.

\begin{tabular}{cccccc}
\hline Load (MPa) & SSSS & CCCC & CSCS & CFCF & HHHH \\
\hline 0.1 & 1.1907 & 0.1451 & 1.0537 & 4.8070 & 0.2410 \\
0.2 & 2.3814 & 0.2901 & 2.1074 & 9.6141 & 0.4820 \\
0.3 & 3.5720 & 0.4352 & 3.1611 & 14.4211 & 0.7230 \\
0.4 & 4.7627 & 0.5803 & 4.2148 & 19.2282 & 0.9640 \\
0.5 & 5.9534 & 0.7253 & 5.2685 & 24.0352 & 1.2050 \\
0.6 & 7.1441 & 0.8704 & 6.3222 & 28.8423 & 1.4460 \\
\hline
\end{tabular}




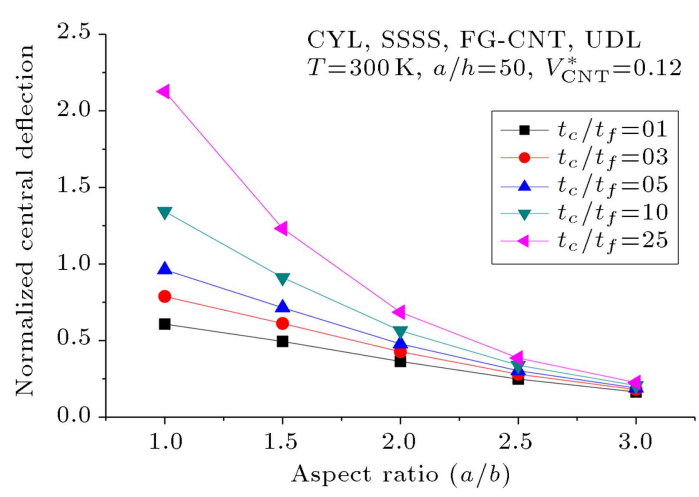

(a)

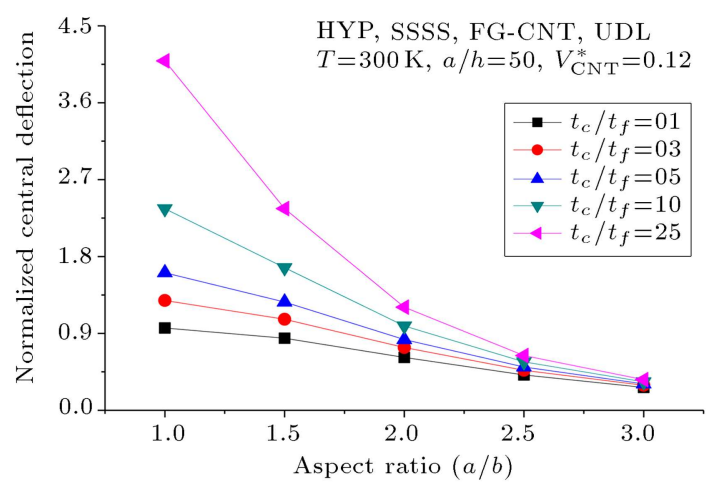

(c)

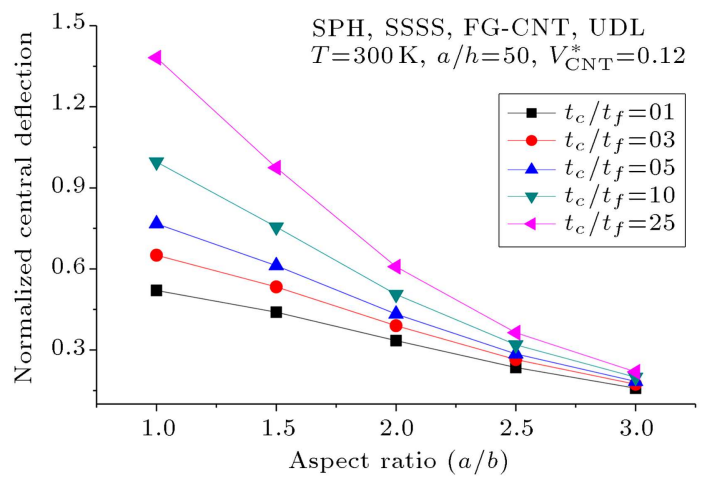

(b)

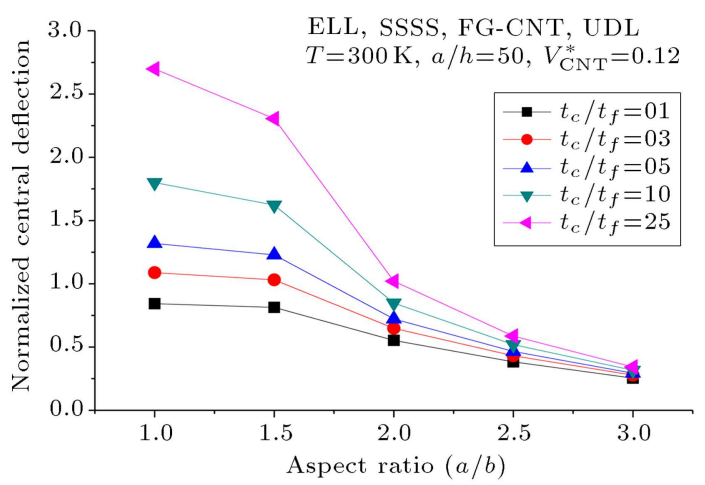

(d)

Figure 5. Effect of the aspect ratio on normalized central deflections of FG-CNT-reinforced sandwich curved panel.

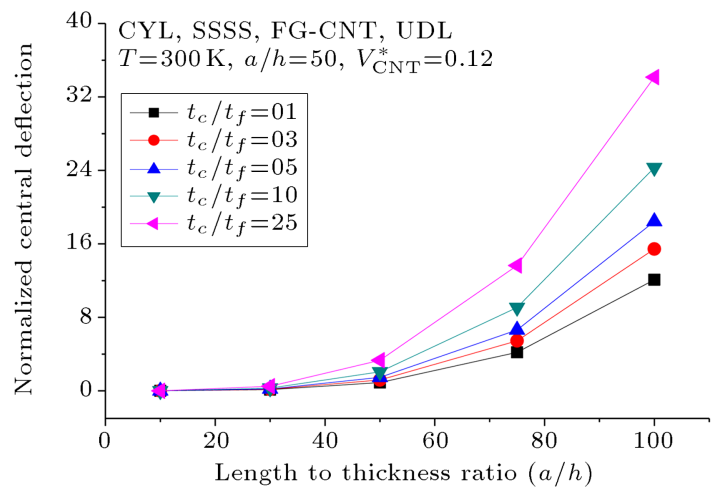

(a)

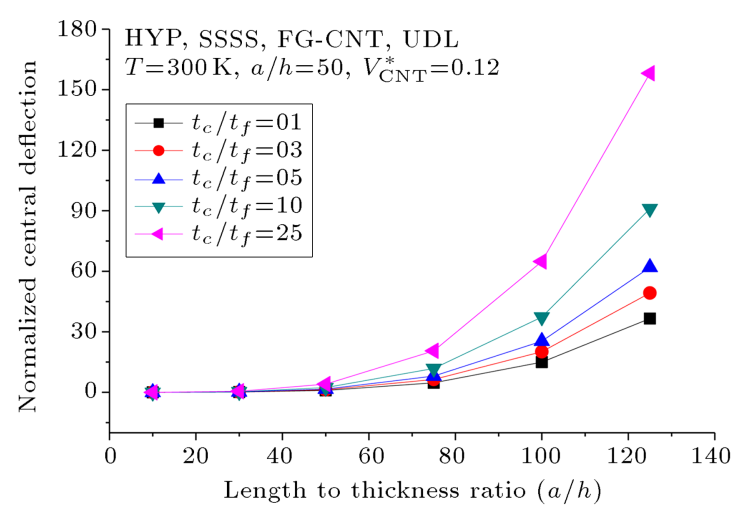

(c)

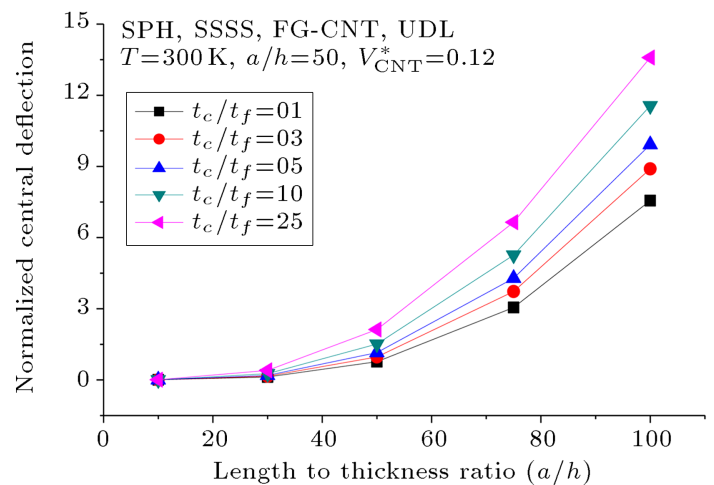

(b)

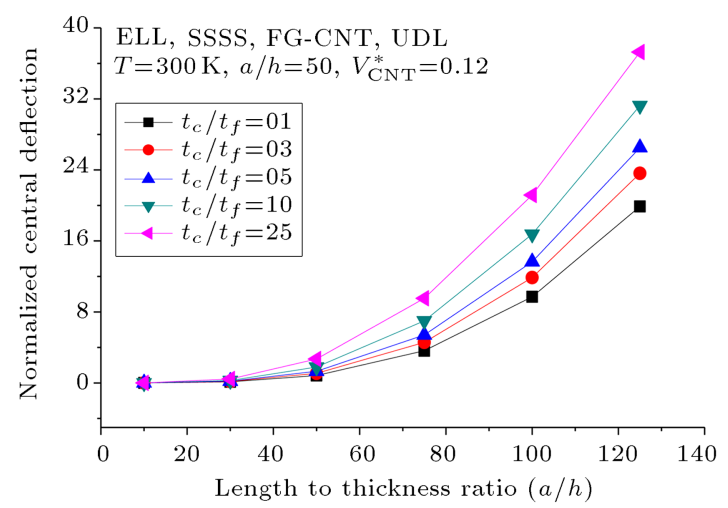

(d)

Figure 6. Comparison of the normalized central deflections of FG-CNT-reinforced sandwich curved shell panel for different types of geometrical configurations. 
sandwich curved panel linearly increases with the rise of applied mechanical load.

\subsubsection{Effect of temperature variation}

In the present study, the CNT and PMMA properties are evaluated via the polynomial equation, as discussed earlier in the analysis. Hence, the thermal loading is one of the key factors in the evaluation of stiffness of the CNT-reinforced sandwich panel. The deflection values of FG-CNT-reinforced sandwich structure, all sides simply-supported, are computed using the current model and presented in Table 4, including temperature loading for four geometrical configurations. The current result pattern is expected because the stiffness of CNT decreases when the effect of temperature increases.

Further, the normalized central deflections of the UD-CNT-reinforced cylindrical curved panel are computed for the linear temperature distribution by assuming the bottom surface temperature $\left(T_{b}\right)$ as $300 \mathrm{~K}$. In addition, the top face of the panel is assumed to expose four different temperature values (400 K, $500 \mathrm{~K}, 600 \mathrm{~K}$, and $700 \mathrm{~K}$ ). Now, using the values of the temperature of the top and bottom surfaces of the panel structure, the desired linear profile is achieved. Further, the responses are computed using the presently developed higher-order model and are provided in Table 5. It is clear from the results that

Table 4. Effect of temperature load on normalized central deflection of CNT reinforced sandwich curved panel (SSSS, FG-CNT, $T=300 \mathrm{~K}, R / a=5, a / h=50, a / b=1$, and $\left.V_{\mathrm{CNT}}^{*}=0.12\right)$.

\begin{tabular}{|c|c|c|c|c|c|c|c|c|c|}
\hline \multirow{2}{*}{ Geometry } & \multirow{2}{*}{$t_{c} / t_{f}$} & \multicolumn{4}{|c|}{ UDL } & \multicolumn{4}{|c|}{ SDL } \\
\hline & & $300 \mathrm{~K}$ & $400 \mathrm{~K}$ & $500 \mathrm{~K}$ & $700 \mathrm{~K}$ & $300 \mathrm{~K}$ & $400 \mathrm{~K}$ & $500 \mathrm{~K}$ & $700 \mathrm{~K}$ \\
\hline \multirow{5}{*}{ CYL } & 1 & 0.9061 & 0.9355 & 0.9614 & 1.0247 & 0.6077 & 0.6317 & 0.6552 & 0.7185 \\
\hline & 3 & 1.1907 & 1.2339 & 1.2726 & 1.3604 & 0.7881 & 0.8215 & 0.8539 & 0.9365 \\
\hline & 5 & 1.4674 & 1.5272 & 1.5824 & 1.7051 & 0.9623 & 1.0065 & 1.0500 & 1.1574 \\
\hline & 10 & 2.0746 & 2.1818 & 2.2873 & 2.5265 & 1.3426 & 1.4169 & 1.4928 & 1.6777 \\
\hline & 25 & 3.3298 & 3.5807 & 3.8548 & 4.5407 & 2.1264 & 2.2906 & 2.4722 & 2.9403 \\
\hline \multirow{5}{*}{ SPH } & 1 & 0.7667 & 0.8039 & 0.8407 & 0.9320 & 0.5201 & 0.5487 & 0.5787 & 0.6588 \\
\hline & 3 & 0.9705 & 1.0239 & 1.0782 & 1.2092 & 0.6505 & 0.6900 & 0.7318 & 0.8403 \\
\hline & 5 & 1.1540 & 1.2255 & 1.3000 & 1.4807 & 0.7671 & 0.8183 & 0.8733 & 1.0157 \\
\hline & 10 & 1.5154 & 1.6313 & 1.7586 & 2.0814 & 0.9958 & 1.0752 & 1.1641 & 1.3993 \\
\hline & 25 & 2.1252 & 2.3419 & 2.5998 & 3.3319 & 1.3816 & 1.5244 & 1.6957 & 2.1905 \\
\hline \multirow{5}{*}{ HYP } & 1 & 0.9627 & 0.9877 & 1.0078 & 1.0575 & 0.6442 & 0.6656 & 0.6858 & 0.7411 \\
\hline & 3 & 1.2858 & 1.3220 & 1.3515 & 1.4168 & 0.8485 & 0.8778 & 0.9048 & 0.9742 \\
\hline & 5 & 1.6105 & 1.6608 & 1.7030 & 1.7925 & 1.0523 & 1.0909 & 1.1266 & 1.2145 \\
\hline & 10 & 2.3604 & 2.4533 & 2.5373 & 2.7157 & 1.5207 & 1.5865 & 1.6495 & 1.7981 \\
\hline & 25 & 4.0901 & 4.3326 & 4.5802 & 5.1542 & 2.5969 & 2.7563 & 2.9221 & 3.3228 \\
\hline \multirow{5}{*}{ ELL } & 1 & 0.8427 & 0.8762 & 0.9076 & 0.9843 & 0.5678 & 0.5943 & 0.6210 & 0.6923 \\
\hline & 3 & 1.0885 & 1.1374 & 1.1843 & 1.2936 & 0.7242 & 0.7610 & 0.7983 & 0.8938 \\
\hline & 5 & 1.3192 & 1.3861 & 1.4520 & 1.6046 & 0.8700 & 0.9184 & 0.9683 & 1.0937 \\
\hline & 10 & 1.8001 & 1.9147 & 2.0344 & 2.3212 & 1.1723 & 1.2511 & 1.3355 & 1.5492 \\
\hline & 25 & 2.6985 & 2.9389 & 3.2141 & 3.9486 & 1.7361 & 1.8937 & 2.0758 & 2.5731 \\
\hline
\end{tabular}

Table 5. Normalized central deflection of UD-CNT-reinforced cylindrical sandwich curved panel under linear temperature distribution (SSSS, UD-CNT, $T_{b}=300 \mathrm{~K}, R / a=5, a / h=50, a / b=1$, and $V_{\mathrm{CNT}}^{*}=0.12$ ).

\begin{tabular}{|c|c|c|c|c|c|c|c|c|}
\hline \multirow{2}{*}{$\frac{t_{c}}{t_{f}}$} & \multicolumn{4}{|c|}{ UDL } & \multicolumn{4}{|c|}{ SDL } \\
\hline & $T_{t}=400 \mathrm{~K}$ & $500 \mathrm{~K}$ & $600 \mathrm{~K}$ & $700 \mathrm{~K}$ & $400 \mathrm{~K}$ & $500 \mathrm{~K}$ & $600 \mathrm{~K}$ & $700 \mathrm{~K}$ \\
\hline 1 & 1.16023 & 1.17768 & 1.19456 & 1.21285 & 0.77188 & 0.78612 & 0.80068 & 0.81710 \\
\hline 3 & 1.37628 & 1.39879 & 1.42085 & 1.44502 & 0.90830 & 0.92594 & 0.94404 & 0.96456 \\
\hline 5 & 1.62832 & 1.65803 & 1.68760 & 1.72022 & 1.06664 & 1.08899 & 1.11205 & 1.13824 \\
\hline 10 & 2.21879 & 2.27051 & 2.32358 & 2.38279 & 1.43627 & 1.47266 & 1.51084 & 1.55425 \\
\hline 25 & 3.49702 & 3.62012 & 3.75286 & 3.90408 & 2.23434 & 2.31549 & 2.40376 & 2.50522 \\
\hline
\end{tabular}


the normalized central deflections follow an increasing line when the temperature value increases.

\subsubsection{Deformed shape of FG-CNT reinforced sandwich panel}

Figure 7 shows the deformed shape of the FG-CNT reinforced sandwich cylindrical panel at $300 \mathrm{~K}$ for different support conditions with other design parameters $\left(a / h=50, R / a=5, a / b=2, t_{c} / t_{f}=3\right.$ and $\left.V_{\mathrm{CNT}}^{*}=0.12\right)$ under UDL $(p=0.1 \mathrm{MPa})$. In Figure 7 , it is clear that the central deflection is the lowest for the CCCC support condition owing to the maximum numbers of constraints associated with it.

\section{Conclusions}

The static behaviour of the CNT reinforced sandwich curved panel based on the higher-order kinematic model was examined under mechanical and thermomechanical loadings. The governing equation of the developed higher-order kinematic model was discretised by finite-element steps and was solved using the MATLAB environment.

Finally, effects of the different designs were examined and concluded the following points:

a. The convergence and comparison analysis indicates the stability and reliability of the developed higherorder sandwich model under thermal environment;

b. The normalized central deflection decreases when the volume fraction and the aspect ratio increases. However, the responses follow a reverse trend for the thermal load, curvature ratio, length-to-thickness ratio, and core-to-face thickness ratio;
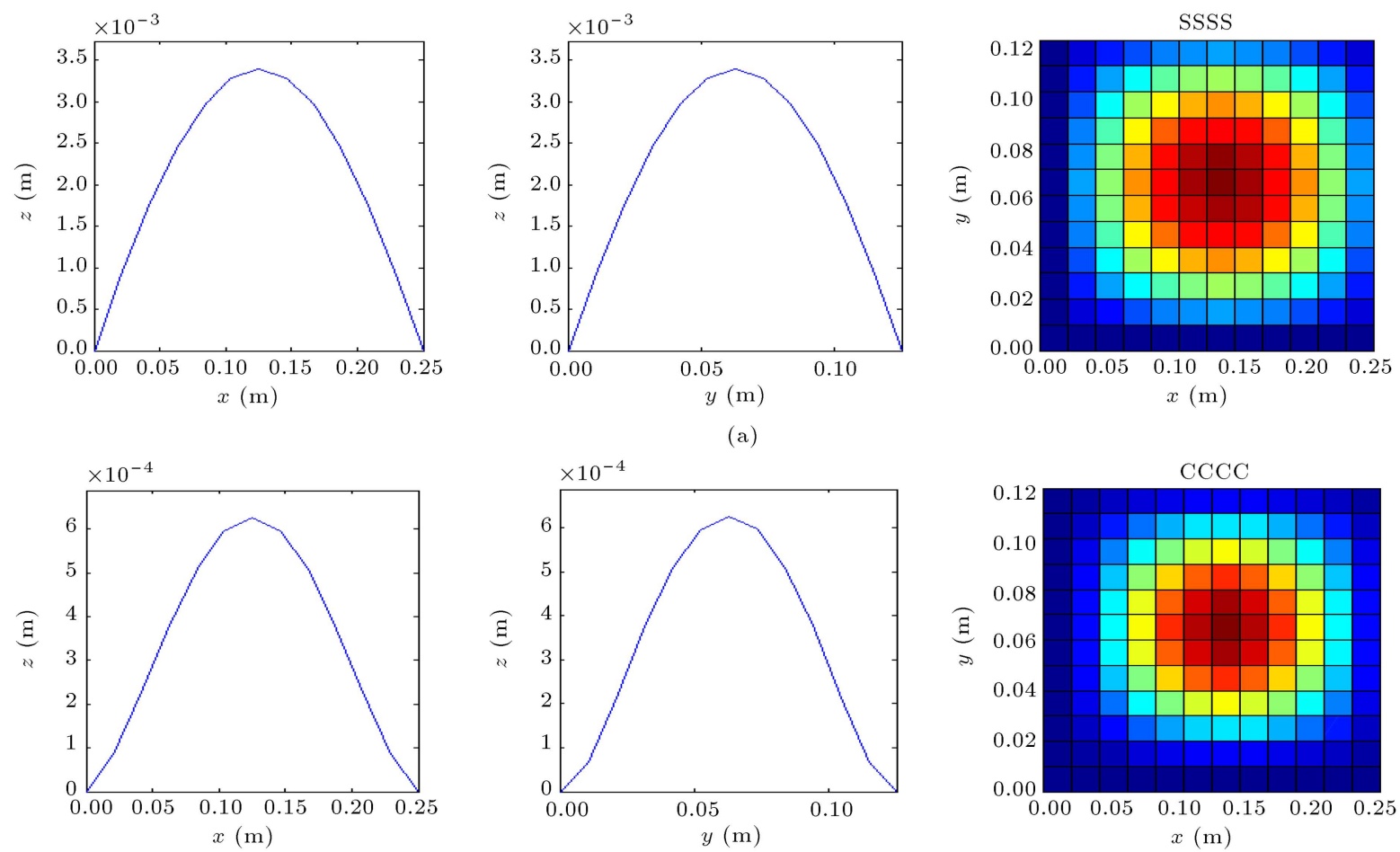

(a)
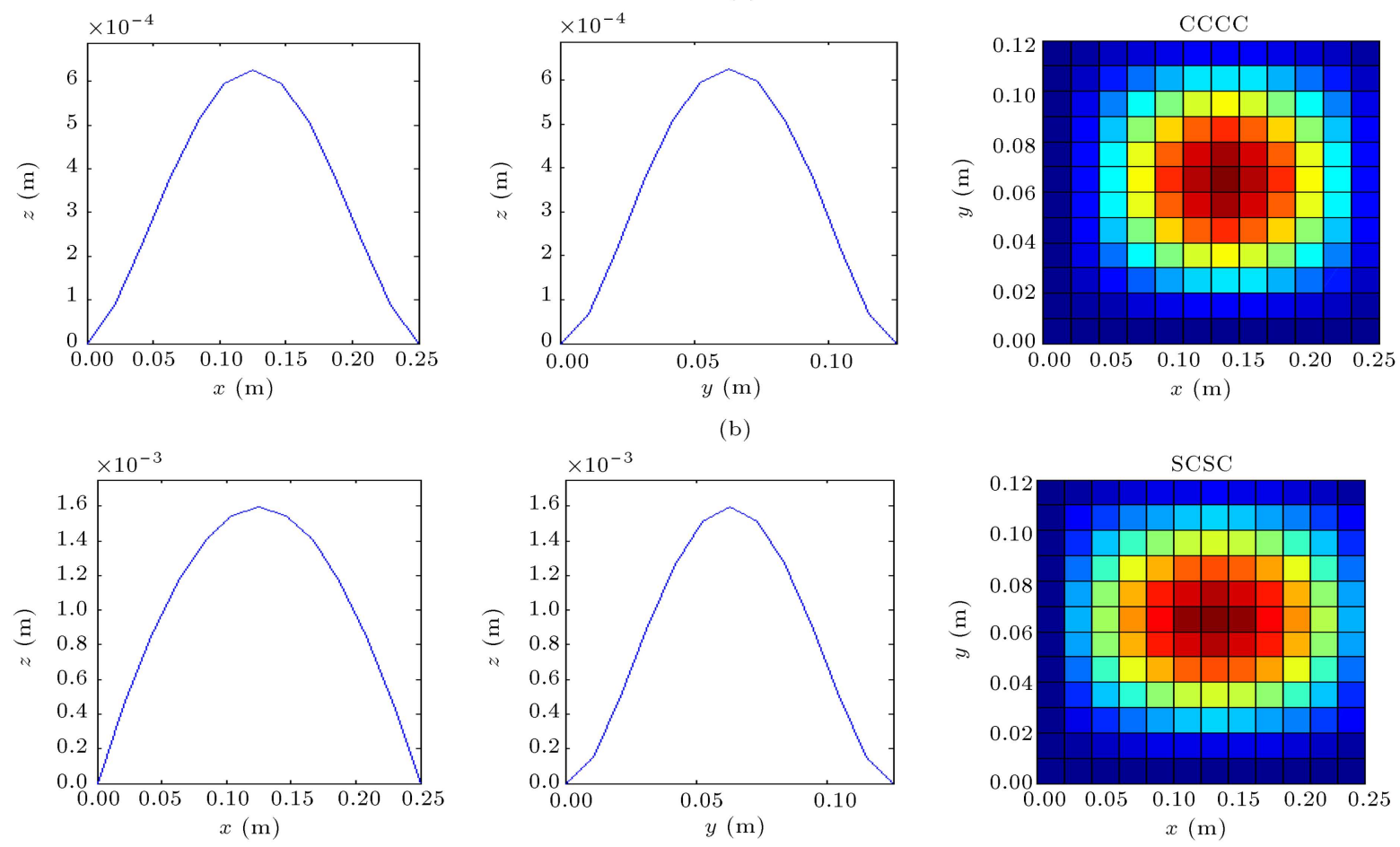

(c)

Figure 7. The deform shape of FG-CNT-reinforced sandwich cylindrical panel for different support conditions (CYL, $\mathrm{UDL}, a / h=50, R / a=5, a / b=2, t_{c} / t_{f}=3, V_{\mathrm{CNT}}^{*}=0.12, p=0.1 \mathrm{MPa}$ and $\left.T=300 \mathrm{~K}\right)$. 
c. The FG-CNT grading configuration is much stiffer than the UD-CNT grading configuration;

d. It is also observed that the spherical geometry is the stiffest geometry as compared to all other geometries;

e. The normalized central deflection is higher for the uniformly distributed load as compared to sinusoidal distributed load.

\section{References}

1. Davies, G.A.O. and Olsson, R. "Impact on composite structures", Aeronaut. J., 108(1089), pp. 541-563 (2004).

2. Houari, M.S.A., Benyoucef, S., Mechab, I., Tounsi, A., and Bedia, E.A.A. "Two-variable refined plate theory for thermoelastic bending analysis of functionally graded sandwich plates", J. Therm. Stress., 34(4), pp. 315-334 (2011).

3. Bouiadjra, M.B., Houari, M.S.A., and Tounsi, A. "Thermal buckling of functionally graded plates according to a four-variable refined plate theory", $J$. Therm. Stress, 35(8), pp. 677-694 (2012).

4. Tlidji, Y., Daouadji, T.H., Hadji, L., Tounsi, A., and Bedia, E.A.A. "Elasticity solution for bending response of functionally graded sandwich plates under thermomechanical loading", J. Therm. Stress., 37(7), pp. 852-869 (2014).

5. Bouderba, B., Houari, M.S.A. and Tounsi, A. "Thermomechanical bending response of FGM thick plates resting on winkler-pasternak elastic foundations", Steel Compos. Struct., 14(1), pp. 85-104 (2013).

6. Mirzaei, M. and Kiani, Y. "Snap-through phenomenon in a thermally postbuckled temperature dependent sandwich beam with FG-CNTRC face sheets", Compos. Struct., 134, pp. 1004-1013 (2015).

7. Mirzaei, M. and Kiani, Y. "Free vibration of functionally graded carbon nanotube reinforced composite cylindrical panels", Compos. Struct., 142, pp. 45-56 (2016).

8. Kiani, Y. "Free vibration of FG-CNT reinforced composite skew plates", Aerosp. Sci. Technol., 58, pp. 178188 (2016).

9. Mirzaei, M. and Kiani, Y. "Free vibration of functionally graded carbon-nanotube-reinforced composite plates with cutout", Beilstein J. Nanotechnol., 7, pp. 511-523 (2016).

10. Kiani, Y. "Free vibration of FG-CNT reinforced composite spherical shell panels using Gram-Schmidt shape functions", Compos. Struct., 159, pp. 368-381 (2017).

11. Mehar, K., Panda, S.K., Dehengia, A., and Kar, V.R. "Vibration analysis of functionally graded carbon nanotube reinforced composite plate in thermal environment", J. Sandw. Struct. Mater., 18(2), pp. 151$173(2016)$.
12. Mohammadimehr, M. and Mostafavifar, M. "Free vibration analysis of sandwich plate with a transversely flexible core and FG-CNTs reinforced nanocomposite face sheets subjected to magnetic field and temperature-dependent material properties using SGT", Compos. Part B Eng., 94, pp. 253-70 (2016).

13. Liu, Y.J. and Chen, X.L. "Evaluations of the effective material properties of carbon nanotube-based composites using a nanoscale representative volume element", Mech. Mater., 35, pp. 69-81 (2003).

14. Han, Y. and Elliott, J. "Molecular dynamics simulations of the elastic properties of polymer/carbon nanotube composites", Comput. Mater. Sci., 39(2), pp. 315-323 (2007).

15. Gardea, F. and Lagoudas, D.C. "Characterization of electrical and thermal properties of carbon nanotube/epoxy composites", Compos. Part B Eng., 56, pp. 611-620 (2014).

16. Aragh, B.S., Barati, A.H.N., and Hedayati, H. "Eshelby-Mori-Tanaka approach for vibrational behavior of continuously graded carbon nanotube-reinforced cylindrical panels", Compos. Part B, 43(4), pp. 19431954 (2012).

17. Zidi, M., Tounsi, A., Houari, M.S.A., Adda Bedia, E.A., and Beg, O.A. "Bending analysis of FGM plates under hygro-thermo-mechanical loading using a four variable refined plate theory", Aerosp. Sci. Technol., 34(1), pp. 24-34 (2014).

18. Tounsi, A., Houari, M.S.A., Benyoucef, S., and Bedia, E.A.A. "A refined trigonometric shear deformation theory for thermoelastic bending of functionally graded sandwich plates", Aerosp. Sci. Technol., 24(1), pp. 209-220 (2013).

19. Mahi, A., Bedia, E.A.A., and Tounsi, A. "A new hyperbolic shear deformation theory for bending and free vibration analysis of isotropic, functionally graded, sandwich and laminated composite plates", Appl. Math. Model., 39(9), pp. 2489-2508 (2015).

20. Bellifa, H., Halim, K., Hadji, B.L., Houari, M.S.A., and Tounsi, A. "Bending and free vibration analysis of functionally graded plates using a simple shear deformation theory and the concept the neutral surface position", J. Brazilian Soc. Mech. Sci. Eng., 38, pp. 265-275 (2016).

21. Bennoun, M., Houari, M.S.A., and Tounsi, A. "A novel five variable refined plate theory for vibration analysis of functionally graded sandwich plates", Mech. Adv. Mater. Struct., 23(4), pp. 423-431 (2016).

22. Hamidi, A., Houari, M.S.A., Mahmoud, S.R. and Tounsi, A. "A sinusoidal plate theory with 5-unknowns and stretching effect for thermomechanical bending of functionally graded sandwich plates", Steel Compos. Struct., 18(1), pp. 235-253 (2015). 
23. Shen, H.S. and Zhu, Z.H. "Postbuckling of sandwich plates with nanotube-reinforced composite face sheets resting on elastic foundations", Eur. J. Mech. A/Solids, 35, pp. 10-21 (2012).

24. Xiang, S., Wang, K.M., Ai, Y.T., Sha, Y.D., and Shi, H. "Analysis of isotropic, sandwich and laminated plates by a meshless method and various shear deformation theories", Compos. Struct., 91(1), pp. 31-37 (2009).

25. Nayak, A.K., Moy, S.S.J., and Shenoi, R.A. "Free vibration analysis of composite sandwich plates based on Reddy's higher-order theory", Compos. Part B Eng., 33(7), pp. 505-519 (2002).

26. Shiau, L.C. and Kuo, S.Y. "Thermal buckling of composite sandwich plates", Mech. Based Des. Struct. Mach., 32(1), pp. 57-72 (2004).

27. Zenkour, A.M. "A comprehensive analysis of functionally graded sandwich plates: Part 1- Deflection and stresses", Int. J. Solids Struct., 42(18-19), pp. 5224$5242(2005)$.

28. Zenkour, A.M. "A comprehensive analysis of functionally graded sandwich plates: Part 2-Buckling and free vibration", Int. J. Solids Struct, 42(18-19), pp. 52435258 (2005).

29. Yang, J., Kitipornchai, S., and Liew, K.M. "Nonlinear local bending of FGM sandwich plates", J. Mech. Mater. Struct., 3(10), pp. 1977-1992 (2008).

30. Imrak, E. and Fetvaci, C. "The deflection solution of a clamped rectangular thin plate carrying uniformly load", Mech. Based Des. Struct. Mach., 37(4), pp. 462474 (2009).

31. Chandrashekhar, M. and Ganguli, R. "Nonlinear vibration analysis of composite laminated and sandwich plates with random material properties", Int. J. Mech. Sci., 52(7), pp. 874-891 (2010).

32. Sadighi, M., Benvidi, M., and Eslami, M. "Improvement of thermo-mechanical properties of transversely flexible sandwich panels by functionally graded skins", J. Sandw. Struct. Mater., 13(5), pp. 539-577 (2011).

33. Kiani, Y., Bagherizadeh, E., and Eslami, M.R. "Thermal and mechanical buckling of sandwich plates with FGM face sheets resting on the Pasternak elastic foundation", Proc. Inst. Mech. Eng. Part C J. Mech. Eng. Sci., 226(1), pp. 32-41 (2012).

34. Mantari, J.L., Oktem, A.S., and Soares, C.G. "Static and dynamic analysis of laminated composite and sandwich plates and shells by using a new higher-order shear deformation theory", Compos. Struct., 94(1), pp. 37-49 (2011).

35. Hadji, L., Atmane, H.A., Tounsi, A., Mechab, I., and Addabedia, E.A. "Free vibration of functionally graded sandwich plates using four-variable refined plate theory", Appl. Math. Mech., 32(7), pp. 925-942 (2011).
36. Khalili, S.M.R. and Mohammadi, Y. "Free vibration analysis of sandwich plates with functionally graded face sheets and temperature-dependent material properties: A new approach", Eur. J. Mech. A/Solids, 35, pp. 61-74 (2012).

37. Natarajan, S. and Manickam, G. "Bending and vibration of functionally graded material sandwich plates using an accurate theory", Finite Elem. Anal. Des., 57, pp. 32-42 (2012).

38. Kavalur, P., Jeyaraj, P., and Babu, G.R. "Static behaviour of visco-elastic sandwich plate with nanocomposite facings under mechanical load", Procedia Mater. Sci., 5, pp. 1376-1384 (2014).

39. Tornabene, F., Fantuzzi, N., Bacciocchi, M., and Viola, E. "Effect of agglomeration on the natural frequencies of functionally graded carbon nanotubereinforced laminated composite doubly-curved shells", Compos. Part B Eng., 89, pp. 187-218 (2016).

40. Szekrenyes, A. "Stress and fracture analysis in delaminated orthotropic composite plates using third-order shear deformation theory", Appl. Math. Model., 38, pp. 3897-3916 (2014).

41. Saha, K.N., Misra, D., Ghosal, S., and Pohit, G. "Nonlinear free vibration analysis of square plates with various boundary conditions", J. Sound Vib., 287, pp. 1031-1044 (2005).

42. Topal, U. and Uzman, U. "Effects of nonuniform boundary conditions on the buckling load optimization of laminated composite plates", Mater. Des., 30(3), pp. $710-717$ (2009).

43. Topal, U. and Uzman, U. "Thermal buckling load optimization of angle-ply laminated cylindrical shells", Mater. Des., 30(3), pp. 532-536 (2009).

44. Apalak, M.K., Yildirim, M., and Ekici, R. "Layer optimisation for maximum fundamental frequency of laminated composite plates for different edge conditions", Compos. Sci. Technol., 68(2), pp. 537-550 (2008).

45. Mehar, K. and Panda, S.K. "Thermal free vibration behavior of FG-CNT reinforced sandwich curved panel using finite element method", Polym. Compos. (2017). DOI: http://dx.doi.org/10.1002/pc.24266.

46. Mehar, K. and Panda, S.K. "Numerical investigation of nonlinear thermomechanical deflection of functionally graded CNT reinforced doubly curved composite shell panel under different mechanical loads", Compos. Struct., 161, pp. 287-298 (2017).

47. Zhu, P., Lei, Z.X., and Liew, K.M. "Static and free vibration analyses of carbon nanotube-reinforced composite plates using finite element method with first order shear deformation plate theory", Compos. Struct., 94(4), pp. 1450-1460 (2012). 
48. Moradi-Dastjerdi, R., Payganeh, G., and Tajdari, M. "Thermoelastic analysis of functionally graded cylinders reinforced by wavy CNT using a meshfree method", Polym. Compos., 39(7), pp. 2190-2201 (2016). DOI: $10.1002 /$ pc. 24183 .

49. Fazzolari, F.A. "Natural frequencies and critical temperatures of functionally graded sandwich plates subjected to uniform and non-uniform temperature distributions", Compos. Struct., 121, pp. 197-210 (2015).

50. Mehar, K. and Panda, S.K. "Free vibration and bending behaviour of CNT reinforced composite plate using different shear deformation theory", IOP Conf. Ser. Mater. Sci. Eng., 115, pp. 012014(1-16) (2016). DOI: $10.1088 / 1757-899 \mathrm{X} / 115 / 1 / 012014$

51. Mahapatra, T.R., Panda, S.K., and Kar, V.R. "Nonlinear flexural analysis of laminated composite flat panel under hygro-thermo-mechanical loading", Int. J. Comput. Methods, 13(3), pp. 1650015 (2016).

52. Mehar, K. and Panda, S.K. "Geometrical nonlinear free vibration analysis of FG-CNT reinforced composite flat panel under uniform thermal field", Compos. Struct., 143, pp. 336-346 (2016).

53. Cook, R.D., Malkus, D.S., Plesha, M.E., and Witt, R.J., Concepts and Applications of Finite Element Analysis, John Wiley \& Sons Pvt. Ltd., Singapore (2009).

54. Mehar, K. and Panda, S.K. "Thermoelastic analysis of FG-CNT reinforced shear deformable composite plate under various loadings", Int. J. Comput. Methods, 14(2), pp. 1750019 (2017).

55. Shen, H.S. and Zhang, C.L. "Thermal buckling and postbuckling behavior of functionally graded carbon nanotube-reinforced composite plates", Mater. Des., 31(7), pp. 3403-3411 (2010).

56. Mirzaei, M. and Kiani, Y. "Thermal buckling of temperature dependent FG-CNT reinforced composite plates", Meccanica, 51(9), pp. 2185-2201 (2016).

57. Reddy, J.N. and Liu, C.F. "A higher-order shear deformation theory of laminated elastic shells", Int. J. Eng. Sci., 23(3), pp. 319-330 (1985).

58. Ferreira, A.J.M., Carrera, E., Cinefra, M., and Roque, C.M.C. "Analysis of laminated doubly-curved shells by a layerwise theory and radial basis functions collocation, accounting for through-the-thickness deformations", Comput. Mech., 48(1), pp. 13-25 (2011).

59. Thai, H.T., Nguyen, T.K., Vo, T.P., and Lee, J. "Analysis of functionally graded sandwich plates using a new first-order shear deformation theory", Eur. J. Mech. - A/Solids, 45, pp. 211-225 (2014).

\section{Appendix}

Strain terms at mid-plane:

$$
\begin{aligned}
& \{\bar{\varepsilon}\}=\left[\begin{array}{lllll}
\varepsilon_{x}^{0} & \varepsilon_{y}^{0} & \varepsilon_{x y}^{0} & \varepsilon_{z x}^{0} & \varepsilon_{y z}^{0}
\end{array}\right. \\
& \varsigma_{x} \quad \varsigma_{y} \quad \varsigma_{x y} \quad \varsigma_{z x} \quad \varsigma_{y z} \\
& \zeta_{x} \quad \zeta_{y} \quad \zeta_{x y} \quad \zeta_{z x} \quad \zeta_{y z} \\
& \left.\xi_{x} \quad \xi_{y} \quad \xi_{x y} \quad \xi_{z x} \quad \xi_{y z}\right]^{T}, \\
& \varepsilon_{x}^{0}=u_{, x}, \quad \varepsilon_{x}^{0}=u_{, x}, \quad \varepsilon_{y}^{0}=v_{, y}, \\
& \gamma_{x y}^{0}=u_{, y}+v_{, x}, \quad \gamma_{z x}^{0}=\varphi_{x}+w_{, x}, \\
& \gamma_{y z}^{0}=\theta_{y}+w_{, y}, \quad \varsigma_{x}^{1}=\varphi_{x, x}, \\
& \varsigma_{y}^{1}=\varphi_{y, y}, \quad \varsigma_{x y}^{1}=\varphi_{x, y}+\varphi_{y, x}, \\
& \varsigma_{z x}^{1}=2 \psi_{x}-\varphi_{x} / R_{x}, \quad \varsigma_{y z}^{1}=2 \psi_{y}-\varphi_{y} / R_{y}, \\
& \zeta_{x}^{2}=\psi_{x, x}, \quad \zeta_{y}^{2}=\psi_{y, y} \\
& \zeta_{x y}^{2}=\psi_{x, y}+\psi_{y, x}, \quad \zeta_{z x}^{2}=3 \theta_{x}-\psi_{x} / R_{x} \\
& \zeta_{y z}^{2}=3 \theta_{y}-\psi_{y} / R_{y} \quad \xi_{x}^{3}=\theta_{x, x} \\
& \xi_{y}^{3}=\theta_{y, y}, \quad \xi_{x y}^{3}=\theta_{x, y}+\theta_{y, x}, \\
& \xi_{z x}^{3}=-\theta_{x} / R_{x}, \quad \xi_{y z}^{3}=-\theta_{y} / R_{y},
\end{aligned}
$$

where:

$$
\begin{aligned}
& u_{, x}=\frac{\partial u_{0}}{\partial x}+\frac{w}{R_{x}}, \quad v_{, y}=\frac{\partial v_{0}}{\partial y}+\frac{w}{R_{y}}, \\
& u_{, y}=\frac{\partial u_{0}}{\partial y}+\frac{w}{R_{x y}}, \quad v_{, x}=\frac{\partial v_{0}}{\partial x}+\frac{w}{R_{x y}}, \\
& w_{, x}=\frac{\partial w_{0}}{\partial x}-\frac{u_{0}}{R_{x}}, \quad w_{, y}=\frac{\partial w_{0}}{\partial y}-\frac{v_{0}}{R_{y}}, \\
& \varphi_{y, y}=\frac{\partial \varphi_{y}}{\partial y}, \quad \varphi_{x, y}=\frac{\partial \varphi_{x}}{\partial y}, \quad \varphi_{y, x}=\frac{\partial \varphi_{y}}{\partial x} \\
& \psi_{x, x}=\frac{\partial \psi_{x}}{\partial x}, \quad \psi_{y, y}=\frac{\partial \psi_{y}}{\partial y}, \quad \psi_{x, y}=\frac{\partial \psi_{x}}{\partial y} \\
& \psi_{y, x}=\frac{\partial \psi_{y}}{\partial x}, \quad \theta_{x, x}=\frac{\partial \theta_{x}}{\partial x}, \quad \theta_{y, y}=\frac{\partial \theta_{y}}{\partial y}, \\
& \theta_{x, y}=\frac{\partial \theta_{x}}{\partial y}, \quad \theta_{y, x}=\frac{\partial \theta_{y}}{\partial x} .
\end{aligned}
$$


Thickness coordinate matrix:

$$
[H]=\left[\begin{array}{cccccccccccc}
1 & 0 & 0 & 0 & 0 & z & 0 & 0 & 0 & 0 & & \\
0 & 1 & 0 & 0 & 0 & 0 & z & 0 & 0 & 0 & & \\
0 & 0 & 1 & 0 & 0 & 0 & 0 & z & 0 & 0 & & \\
0 & 0 & 0 & 1 & 0 & 0 & 0 & 0 & z & 0 & & \\
0 & 0 & 0 & 0 & 1 & 0 & 0 & 0 & 0 & z & & \\
z^{2} & 0 & 0 & 0 & 0 & z^{3} & 0 & 0 & 0 & 0 \\
0 & z^{2} & 0 & 0 & 0 & 0 & z^{3} & 0 & 0 & 0 \\
0 & 0 & z^{2} & 0 & 0 & 0 & 0 & z^{3} & 0 & 0 \\
0 & 0 & 0 & z^{2} & 0 & 0 & 0 & 0 & z^{3} & 0 \\
0 & 0 & 0 & 0 & z^{2} & 0 & 0 & 0 & 0 & z^{3}
\end{array}\right] .
$$

\section{Biographies}

Kulmani Mehar, the lead author of this article, is currently pursuing the doctoral research in the field of theoretical and experimental mechanics of composite material. The research contribution includes the modelling of functionally graded CNT reinforced composite structure and experimental evaluation of structural responses. In addition, he is working in the field of numerical evaluation of structural responses using the finite-element method.

Subrata Kumar Panda received his PhD from IIT Kharagpur, India in 2009. He is working as an Associate Professor at the Department of Mechanical Engineering, National Institute of Technology, Rourkela. His current research interest includes nonlinear solid mechanics, smart composite structures, nonlinear FEM, experimental vibrations, functionally graded materials, SMA, PZT, magnetostrictive material, and bio-mechanical analysis of functional materials.

Trupti Ranjan Mahapatra received his $\mathrm{PhD}$ from KIIT University, Bhubaneswar, India in 2015. He is working as an Associate Professor at the Department of Mechanical Engineering, KIIT University, Bhubaneswar, India. His current research interest includes nonlinear behaviour of laminated composite structures using FEM. 